\title{
Beyond decomposition: processing zero- derivations in English visual word recognition
}

Article

Accepted Version

Creative Commons: Attribution-Noncommercial-No Derivative Works 4.0

Wheeldon, L., Schuster, S., Pliatsikas, C., Malpass, D. and Lahiri, A. (2019) Beyond decomposition: processing zeroderivations in English visual word recognition. Cortex, 116. pp. 176-191. ISSN 0010-9452 doi:

https://doi.org/10.1016/j.cortex.2018.09.003 Available at https://centaur.reading.ac.uk/78958/

It is advisable to refer to the publisher's version if you intend to cite from the work. See Guidance on citing.

To link to this article DOI: http://dx.doi.org/10.1016/j.cortex.2018.09.003

Publisher: Elsevier

All outputs in CentAUR are protected by Intellectual Property Rights law, including copyright law. Copyright and IPR is retained by the creators or other copyright holders. Terms and conditions for use of this material are defined in the End User Agreement.

www.reading.ac.uk/centaur 
Central Archive at the University of Reading

Reading's research outputs online 


\section{AUTHORS' ACCEPTED VERSION}

To appear in Cortex

Beyond decomposition: processing zero-derivations in English visual word recognition

Linda Wheeldon ${ }^{1}$, Swetlana Schuster ${ }^{2}$, Christos Pliatsikas ${ }^{3}$, Debra Malpass ${ }^{4}$ and Aditi Lahiri $^{4}$

1 University of Agder

2 University of Oxford

3 School of Psychology and Clinical Language Sciences, University of Reading

4 Solicitors Regulation Authority

Address correspondence to: Dr. Linda Wheeldon, Institute for Foreign Languages and Translation, University of Agder, Gimlemoen 25, 4630 Kristiansand S, Norway E-mail: linda.r.wheeldon@uia.no 
Abstract

Four experiments investigate the effects of covert morphological complexity during visual word recognition. Zero-derivations occur in English in which a change of word class occurs without any change in surface form (e.g., a boat-to boat; to soak-a soak). Boat is object-derived and is a basic noun $(\mathrm{N})$, whereas soak is action-derived and is a basic verb $(\mathrm{V})$. As the suffix $\{$-ing $\}$ is only attached to verbs, deriving boating from its base, requires two steps, $\operatorname{boat}(N)>\operatorname{boat}(V)>\operatorname{boating}(V)$, while soaking can be derived in one step from $\operatorname{soak}(V)$. Experiments 1 to 3 used masked priming at different prime durations to test matched sets of one and two-step verbs for morphological (soaking$S O A K$ ) and semantic priming (jolting-SOAK). Experiment 4 employed a delayedpriming paradigm in which the full verb forms (soaking and boating) were primed by noun and verb phrases (a soak/to soak, a boat/to boat). In both paradigms, different morphological priming patterns were observed for one-step and two-step verbs, demonstrating that morphological processing cannot be reduced to surface form-based segmentation.

Keywords: visual word processing, morphological structure, derivational complexity, masked priming, delayed priming. 
Research on the processing of morphology during the recognition of written words has focused on the issue of if, or how, words are decomposed into their component parts. Evidence has accumulated that the recognition of morphologically complex written words such as disagreement involves their decomposition to their base form, i.e. the stem agree and the affixes dis- and -ment (Taft \& Forster, 1975). This evidence has come from a large number of studies using a variety of behavioural (Longtin \& Meunier, 2005; Marslen-Wilson, Tyler, Waksler \& Older, 1994; Rastle \& Davis, 2008; Rastle, Davis, \& New, 2004; Rastle, Davis, Marslen-Wilson \& Tyler, 2000; Schuster \& Lahiri, 2018) and neurological techniques (Bozic, Marslen-Wilson, Stamatakis, Davis, \& Tyler, 2007; Devlin, Jamison, Matthews, \& Gonnerman, 2004; Marangolo, Piras, Galati, \& Burani, 2006; Lavric, Rastle \& Clapp, 2011; Lavric, Elchlepp \& Rastle, 2012; Meinzer, Lahiri, Flaisch, Hannemann, \& Eulitz, 2009; Pliatsikas, Wheeldon, Lahiri \& Hansen, 2014; Schuster, Scharinger, Brooks, Lahiri \& Hartwigsen, 2018; Whiting, Shtyrov \& Marslen-Wilson, 2014). The aim of much of this research has been to find evidence for independent morphological processes during word recognition that cannot be reduced to the interaction of semantic and form-based factors in the way that has been proposed by connectionist models of lexical processing. According to such models, morphological structure is a by-product of the mapping from surface form to meaning during word processing (e.g., Baayen, Milin, Đurđević, Hendrix \& Marelli, 2011; Davis, van Casteren \& Marslen-Wilson, 2003; Plaut \& Gonnerman, 2000).

The aim of the present research was also to investigate the processing of morphologically complex written words. However, our research differs in two ways from research to date. First, we test the effects of compositional rules of morphology. Speakers know more about word structure than what constitutes a morpheme of their 
language; they also know their compositional restrictions - how morphemes can be legally combined. For example, the suffix $\{$-ize $\}$ is added to certain classes of nouns to create verbs like liquidize, while $\{$-ing $\}$ is usually added to verbs (Spencer 1991).

Second, we focus on covert morphological processes that cannot be limited to decomposition. In most languages nouns $(\mathrm{N})$ can be derived from verbs $(\mathrm{V})$ and vice versa, usually with the addition of an affix to the base (e.g., $\operatorname{liquid}(N)>\operatorname{liquid}$-ize $(V)$ and write $(V)>$ writ-er $(N)$. In English, this change of word class can occur without the addition of an overt affix (e.g., a boat-to boat; to soak-a soak). Boat is object-derived and is a basic noun (N), whereas soak is action-derived and is a basic verb (V) (Plank, 2010). However, the suffix $\{$-ing $\}$ is only attached to verbs. Therefore, to derive boating from its base, two steps are required, namely, $\operatorname{boat}(N)>\operatorname{boat}(V)>\operatorname{boating}(V)$, while $\operatorname{soaking}(V)$ can be derived in one step from soak $(V)$. In Pliatsikas, Wheeldon, Lahiri \& Hansen (2014), we reported an fMRI study showing that the degree of covert morphological complexity in written English words was positively related to the magnitude of the BOLD response in the LIFG but not in posterior regions. These findings are consistent with an early morpho-orthographic decomposition process that is blind to the actual morphological structure of words followed by a lexical morphological process sensitive to stored morphological and semantic information. Here we report four behavioural experiments using both masked, visible and delayed priming paradigms, which were designed to further test this claim.

Current proposals as to how morphological structure affects visual word processing differ largely in when they allow semantic factors to affect decomposition. The proposal of Rastle and colleagues mentioned above is that words are first decomposed during an early pre-lexical decomposition process unaffected by semantics (see Rastle \& Davis, 2008; Rastle, Davis, \& New, 2004). This decomposition is based 
on a morpho-orthographic analysis, which is then followed by the activation of the semantic properties of the words. Critically, this early decomposition process is blind to the underlying morphological relationship between the decomposed stem and affix and therefore the effect cannot be attributed to the activation of shared morphemes but to a relatively superficial affix-spotting procedure. According to this proposal, initially, anything that looks as if it is morphologically complex will be automatically decomposed even if the subparts do not function as morphemes in the word. Support for this proposal has come predominantly from studies using the masked priming paradigm in which forward masked primes are presented for approximately 30 to $40 \mathrm{~ms}$ (so that participants are usually unaware of them). This technique has been used to demonstrate that a complex word will prime its stem (e.g., cleaner-CLEAN) but that a pseudoaffixed word will also prime even though there is no real morphological or semantic relationship between the prime and target (e.g., corner-CORN). This effect cannot be explained in terms of form priming because the same amount of overlap does not result in priming when the final segments do not function as an affix (e.g., brothel-BROTH) (Rastle, et al., 2004; see also McCormick, Rastle \& Davis, 2008; Lavric, et al., 2012; Longtin \& Meunier, 2005; Marslen-Wilson, Bozic \& Randall, 2008; Whiting, et al., 2014). Evidence consistent with early morphological decomposition independent of both semantic and orthographic factors has been found in the visual processing of a number of languages: English (Rastle, et al., 2004; Rastle, et al., 2000), French (e.g., Longtin, Segui \& Halle, 2003) Spanish (e.g., Domínguez, de Vega \& Barber, 2004), Hebrew (e.g., Velan \& Frost, 2011) and Arabic (e.g., Boudelaa \& Marslen-Wilson, 2005).

Clear semantic effects on complex word processing are observed in studies using methodologies in which the morphologically related prime is visible. These 
studies show evidence for morphological priming of transparently related forms (e.g., bravely/brave) but not semantically opaque forms (e.g., apartment/apart) (e.g., Feldman, 2000; Rastle et al., 2000; Feldman \& Soltano, 1999; Longtin et al. 2003; MarslenWilson et al., 1994; Meunier \& Longtin, 2007: see however Smolka, Preller \& Eulitz, 2014). It has been argued that fully visible primes tap into later lexical-morphological processes in which the representation of morphemes is dependent on the relationship between form and meaning: Words are only stored in a decomposed form when their component morphemes are regular in form and semantically transparent; irregular or opaque forms are listed in full. Therefore, agreement will be stored in a decomposed fashion because its meaning can be derived in a transparent way from the combination of its morphemes - the verb stem agree and the noun formation suffix -ment, but apartment will be stored as a whole form as its meaning cannot be derived in the same way (e.g., Marslen-Wilson, et al. 1994).

Alternative theories postulate much earlier effects of semantics on morphological decomposition (e.g., Diependaele, Sandra, \& Grainger, 2005; Feldman, Kostić, Gvozdenović, O’Connor, \& Moscoso del Prado Martín, 2012; Feldman, O’Connor, \& Moscoso del Prado Martín, 2009; Giraudo \& Grainger, 2001; Grainger \& Ziegler, 2011; Plaut \& Gonnerman, 2000; Rueckl \& Raveh, 1999; Rueckl \& Aicher, 2008). Support for the early influence of semantics on decomposition have come from meta-analyses of masked priming studies showing consistently greater priming for semantically related morphological primes (Feldman et al., 2009; also Davis \& Rastle, 2010; Morris, Frank, Grainger, \& Holcomb, 2007). However recent ERP (Barber, Domínguez \& de Vega, 2002; Domínguez, et al., 2004; Lavric, et al. 2011; Lavric, et al. 2012) and MEG studies (Whiting, et al., 2014), designed to track the time course of 
semantic transparency effects have yielded evidence consistent with later effects of semantic information on word processing.

A number of ERP studies have used a methodology similar to masked priming to investigate the effect of primes visible for between 200ms and 300ms (e.g., Barber et al., 2002; Dominguez, et al., 2004; Lavric et al., 2011). For example, Lavric et al. (2011) presented primes for $226 \mathrm{~ms}$ prior to target onset; primes had either a transparent morphological relationship to their stems (magical-MAGIC), a pseudo- or opaque morphological relationship but were semantically unrelated (compassion-COMPASS), or were only orthographically related (brothel-BROTH). RTs showed facilitation for transparent morphological relationships, which was significantly larger than that observed for pseudo-morphological relationships. Although the later effect was also significant, it did not significantly differ from the null effect of orthographic overlap. The ERP data focused on the N400 and showed equivalent attenuation effects for transparent and pseudo- morphological conditions in the early range ( $300-380 \mathrm{~ms})$ that could be distinguished from the orthographic effects. In the later range (380 onwards), the attenuation effect in pseudo-morphological condition reversed to the level of the orthographic condition, whereas the effect in the transparent condition was maintained. Lavric et al. (2011) argued that these data are compatible with a single, early, orthographic-based decomposition mechanism, the output of which is later licensed by the availability of appropriate lexical semantics.

Imaging studies have also yielded results consistent with the hypothesis of the early morpho-orthographic decomposition process followed by the activation of lexical semantics. Paradigms that arguably tap into stored lexical representations have shown effects of derivational complexity in the LIFG. Bozic et al. (2007) used a delayed repetition priming in which prime and target pairs were presented on average 18 items 
(45 sec) apart and participants made a lexical decision response to each item. Delayed priming reduces strategic processing effects as the lag between pairs makes it less likely for participants to detect the relationship between stimuli. Furthermore, earlier studies demonstrated that morphological priming is preserved over long lags while semantic and orthographic priming is attenuated as the number of intervening words increases (Bentin \& Feldman, 1990; Napps \& Fowler, 1987). Bozic and colleagues tested derived pairs where the morphological relationship was semantically transparent (e.g., bravelybrave) or semantically opaque (e.g., archer-arch) as well as pairs with relationships that were purely orthographic (e.g., scandal-scan) or semantic (e.g., accuse-blame). The behavioural data showed significant effect of priming in the morphologically related conditions and no difference between the semantically opaque and transparent pairs. The fMRI data showed significant reductions in activation due to morphological priming in the LIFG. No reduction in activation was observed for targets preceded by purely form or meaning related primes. This finding provides strong support for the central role of the LIFG in the processing of morphologically complex words. Bozic et al., (2007) suggest that the LIFG may be involved in combinatorial operations on the output of an earlier decomposition stage that isolated potential morphemes prior to their mapping onto stored lexical representations.

Moreover, effects have been shown in the LIFG for differences in derivational complexity. Decomposition has usually been tested using a single step derivation e.g., sincere-sincer-ity. However, most languages allow multiple derivations e.g., nation >nation-al>nation-al-ize. Meinzer et al. (2009) examined the effect of the degree of complexity on word recognition processes. They used fMRI to compare the reading of derived German nouns differing in the complexity of their internal structure. The nouns shared suffixes and therefore had the same surface structure but differed in the 
number of steps required for their derivation. Deutung (interpretation) and Milderung (mitigation) look superficially similar, but Deutung is derived in one step from the verb deuten, while Milderung is derived in two steps from the adjective via the verb $(\operatorname{mild}(A)>\operatorname{mildern}(V)>$ Milderung $(N))$. They showed that 2-step derivations elicit more pronounced activity in the LIFG than 1-step derivations. The increased activation for words with complex internal structure supports the assumption that morphologically complex words are decomposed and accessed from the lexicon as stems and affixes and that the LIFG is sensitive to the degree of structural complexity found within words.

In contrast, fMRI studies using masked priming have found no effects of morphological complexity in the LIFG. Instead, effects are found in a left hemisphere network of regions, including the occipito-temporal cortex, middle temporal gyrus, angular and supramarginal gyri, and inferior prefrontal cortex (cf. Devlin, et al., 2004; Gold and Rastle, 2007; Whiting, et al., 2014; for a detailed review, see Leminen et al., 2018). These findings suggest that masked priming may only engage early visual word recognition processes as posterior rather than frontal areas associated with morphological priming tend to become activated.

Covert derivational complexity. All of the research reviewed above has focused on morphological complexity in terms of decomposition and, in the word forms tested, an increase in morphological complexity has been equated to an increase in surface complexity. However, morphological relationships can be established in many ways. The most familiar process among Indo-European languages is overt affixation, including prefixation, suffixation or both: re-work, work-able, re-work-able. Less common, but nevertheless well established, are alterations of segments as in $u s e(N)$ versus $u s e(V)$, where the noun is pronounced with a final [s] and the verb with [z]. Affixation can be accompanied by truncation. For example, the suffix $\{$-ity $\}$ can be 
added directly to an adjective, as in pompous to produce the noun pomposity; however, when $\{$-ity $\}$ is added to enormous, the stem is truncated and the derived form is enormity.

The addition, alteration or deletion of segments is, thus, all part of overt morphological exponents to establish derivational relationships. However, overt marking is not a necessary component of morphological derivation. A covert process of derivation, known as zero-derivation or conversion, can relate morphological pairs without any surface marking: $\operatorname{boat}(N)$ versus $\operatorname{boat}(V)$. This process relating nouns and verbs is both semantically compositional and very productive in English (Aronoff, 1980; Clark \& Clark, 1979; Kiparsky, 1982; Lieber, 1980; Plank, 1981), largely because inflectional suffixes disappeared although they still exist in other Germanic languages. So, for example the Old English verb endian 'to end' was derived from the noun ende 'end'. However, due to the loss of both nominal and verbal suffixes, the present-day English forms are identical. In contrast, German maintains the distinction between the noun and the verb, e.g., Ende( $N)$ versus end-en $(V)$.

Deriving nouns from verbs and vice versa is productive in most languages of the world. Where this derivation is accomplished by the addition of an overt affix, the affixation also indicates the direction of the derivation i.e., it shows which is the base form. For example, critic is a basic noun from which one can derive the verb criticize while write is a basic verb from which we can derive the noun writer. In English, $\{$-ize $\}$ is a verb-forming suffix that attaches to nouns, while $\{$-er $\}$ is a nominalizing suffix that must attach to verbs. However, a potential problem arises with forms that can be zeroderived. The term zero-derivation implies that one member of these pairs is the base form. Historically, for many pairs, the direction of derivation was transparent, but does this relationship persist in the present-day noun-verb pairs when there is no overt suffix? 
It has been proposed that if there is derivational relationship, then the direction of derivation is determined by the semantic properties that are carried over to the derived word (Plank, 2010). So, boat has basic object semantics and is a basic noun so the semantics of the verb forms have to be described with reference to the semantics of the noun. The meaning of the verb boat has to make reference to the related object that does the boating. Similarly, a soak is a derivative of the verb to soak - the action of soaking is inherent in the meaning of $a$ soak. Of course, these relationships are not static and meaning can drift over time such that formally similar words can become semantically opaque in their derivational relationship (e.g., $\operatorname{dress}(N)-\operatorname{dressing}(V)$ in the sense of a bandage; $\operatorname{stuff(}(N)$ - stuffing $(V)$ in the sense of stuffing a turkey). Of course, not all such pairs can be claimed to have a derivational relationship and both the verb and the noun form can be basic (Darby \& Lahiri, 2016). For example, guard can be used as a noun or a verb and it is impossible to say that one form is basic and the other derived. Our claim is not that all related forms must have one word class marked as basic, but that where a clear basic form exists, the derivational relationship must take that into account and this should be reflected in the processing of derived forms.

English allows a variety of $\{$-ing $\}$ forms of which the participial $\{$-ing $\}$, a nonfinite inflectional suffix of verbs, is the most frequent (e.g. She was visiting). Other forms include derived adjectives (e.g. The singing detective), derived action nouns (e.g. The visiting of the relatives was a nuisance) and the denominals deriving collective nouns such as bedding, railing, carpeting. Our intention was to use the participial $\{-$ ing \}, which attaches only to verbs since the central aim was to examine the difference between basic verbs and derived verbs from nouns. As the participial form is the most common and therefore most likely to be activated, context is required to get the other 
readings of our $\{$-ing $\}$ forms. We were careful to avoid denominal and deverbal $\{$-ing $\}$ forms.

The question raised by zero-derivational relationships is, where they still clearly exist, do we compute them during word recognition? Evidence that such computations do occur comes from an fMRI study of visual word recognition. In Pliatsikas et al. (2014), we investigated zero-derivations in English to look for evidence of derivational depth on processing in the absence of overt affixation. As we mentioned above, overt affixes usually attach to specific word classes; for example $\{$-ing $\}$ can attach only to verbs. In instances of zero-derivation, $\{$-ing $\}$ can attach to a base verb, e.g. soaking or to verbs which have been derived from nouns, e.g. boating. These words, therefore, have different derivational depth. Boating has a two-step derivation from its noun stem via an intermediate zero-derived verb form (e.g. boating $<\operatorname{boat}(V)<\operatorname{boat}(N))$, whereas soaking has a one-step derivation, where $\{-$ ing $\}$ is attached directly to the verb root $($ soaking $<\operatorname{soak}(V))$. Importantly, the noun soak exists, but it is not part of this derivation. Of course, zero-derivation is not compulsory; nouns exist which have not formed verbs (e.g., door) and verbs can exist without a corresponding zero-derived noun form (e.g., write). The intermediate step in the two-step derivation of boating is crucial because, the participial $\{$-ing $\}$ can only attach to verbs. Thus, $\{$-ing $\}$ can be added to the verb form boat to form boating but cannot, for example, be added to song, which does not currently have a transparent verb form * to song.

Pliatsikas et al. (2014) tested whether covert derivational complexity is observable in the degree of activation of brain areas associated with morphological processing. Participants made responses to nonwords on a series of one and two-step zero-derived English verbs like boating and soaking and to matched simple forms such as grumble. Taking $\{$-ing $\}$ off any form necessarily leaves a verb. Therefore, the 
processing of the complex word boating would involve two steps to go back to the base noun. In contrast, the processing of soaking requires one-step to get to the base verb. There were two main findings. First, we observed greater activation of the occipital lobe for both our one- and two-step complex forms compared to our monomorphemic control words. Similar effects have been reported in the literature (e.g., Devlin et al., 2004; Gold \& Rastle, 2007) and suggest that this area supports the decomposition of surface morphemes in the visual input i.e., $\{$-ing $\}$-stripping for our one- and two-step words. Second, the two-step forms generated significantly more activity in the LIFG (mainly in pars opercularis) than one-step forms, indicating that morphological processing of the complex forms takes place in this region. We therefore showed a difference in the degree of activation based on derivational depth in the same location within the LIFG. These results are compatible with both the behavioural and neuroimaging data reviewed above and can be explained in terms of an initial morpho-orthographic affix-stripping procedure followed by access to morpho-lexical representations. Critically however, these data are the first to demonstrate effects of covert morphological complexity as superficially similar words showed different effects due to differences in derivational depth determined by the compositional requirements of English.

The current experiments. The experiments reported here were designed to look for behavioural effects of zero-derivation on morphological processing. We conducted three priming experiments, both masked and visible primes, and a delayed priming experiment to test the processing of one-step and two-step derived words (Pliatsikas et al., 2014). As discussed above, delayed priming has been shown to yield effects of morphological relationships in the absence of semantic and form-based priming (Bentin \& Feldman, 1990; Bozic et al. 2007; Napps \& Fowler, 1987; Schuster \& Lahiri, 2018). 
If the difference observed in the LIFG for one-step and two-step derived words is due to the processing of covert morphological complexity, we should also see differences in delayed priming for these words. In contrast, the pattern of results in the masked priming paradigm should be dependent on the duration of the prime word's presentation. If masked priming with a very short prime duration (33ms) taps into a superficial affixstripping process unaffected by stored lexical morphology, we predict no effects of derivational complexity as the pre-lexical decomposition process ( $\{$-ing $\}$-stripping) is identical for both our one-step and two-step derived words. However, if prime duration is increased such that primes become visible to participants $(200 \mathrm{~ms}, 300 \mathrm{~ms})$, we would expect effects of lexical-morphology and semantics to emerge (Lavric et al., 2011). Our one- and two-step verbs are semantically licensed to the same extent, in that they are both transparent and regular; however, they differ in the complexity of the derivational processes required to license them morphologically. If longer prime durations tap into lexical-morphological representations, we would expect to observe effects of underlying morphological complexity that are distinguishable from purely semantic priming effects.

\section{Experiments 1 to 3}

We conducted three priming experiments, which differed only in the duration of the prime presentation. The targets for lexical recognition were the uninflected stems of the one-step and two-step full verb forms (e.g., SOAK and BOAT respectively) and each stem occurred in three priming conditions. All primes were suffixed words related to the target either morphologically (e.g., soaking, boating), semantically (e.g., wetting, rowing) or were unrelated to the target (bossing, thirsting). 
The aim of Experiment 1 was to test the early decomposition processes of the one and two-step verbs tested by Pliatsikas et al. (2014). We therefore used a standard masked priming methodology, with a forward mask immediately prior to prime presentation and a short prime duration $(33 \mathrm{~ms})$. We predicted a significant effect of morphological priming but no effect of semantic priming, and no interaction of morphological priming with derivational complexity. In Experiments 2 and 3, we tested priming at two longer prime durations in order to look for effects of underlying morphological structure and semantic relatedness when the primes were visible. With a prime duration of 226ms, Lavric et al. (2011) observed significant effects of morphological priming for transparent morphological relationships and reduced effects for pseudo/opaque relationships. However, their stimuli do not allow a distinction to be made between effects of lexical-morphology and morpho-semantics. Our one- and twostep stimuli are matched semantically but differ in their derivational morphology. We therefore predict that longer prime durations should yield a significant interaction of derivational depth with morphological priming but not with semantic priming. We tested both priming effects at a prime duration of 200ms and 300ms (Experiments 2 and 3 respectively).

\section{Method}

Materials. The experimental materials were constructed from of two sets of 36 disyllabic words with initial stress. These sets included the stimuli tested by Pliatsikas et al. (2014) with 6 extra added to each group to increase item power (see Appendix 1). One set comprised one-step verbs (e.g., soaking), and the other comprised two-step verbs (e.g., boating). These derived verbs all had stems that could occur as both nouns or verbs. However, all one-step verbs had stem meanings that we judged to be action 
based and therefore basic verbs (e.g., soak), whereas all two-step verbs had stems that we judged to be object based and therefore basic nouns (e.g., boat). These judgments were confirmed by rating data collected from 20 participants using questionnaires. The questionnaires consisted of the stems of experimental items (e.g., boat, soak) along with filler words. Stems were used to prevent the $\{-$ ing $\}$ forms biasing towards verb readings. Participants were asked to rate each word according to the extent to which it referred to an action on a scale from 1 to 9, when 1 represented "cannot refer to an action" and 9 represented "can only refer to an action". Our aim was to estimate the "verbiness" of our stimuli on a single scale. As expected, the one-step stems had significantly higher average action ratings than the two step stems, $p<.0001$ (see Table 1). Table 1 provides a summary of the matching data per morphological condition.

As an additional confirmation of our one- and two-step stimuli groups we extracted the frequencies of the verb stems (e.g., $\operatorname{soak}(V))$ and the noun stems (e.g., $\operatorname{soak}(N))$. Within the derivational relationship we are examining, nouns, in general, have a higher frequency than verbs and this is also true of our experimental stimuli (see Table 1). The two-step stems had significantly higher noun frequencies than verb frequencies $(p<.001)$ as did the one-step stems and the difference was borderline $(p=.05)$. However, we also expected our verb-stem frequencies to be higher for the one-step verbs than the two-step verbs and that our noun-stem frequencies would show the reverse pattern. The verb and noun stem frequencies are the frequency of occurrence of the bare noun and verb stems and do not include any inflected forms. This is because lexical databases do not provide the word class of inflected forms such as soaks, which might be the plural of the noun or the third person of the verb. These numbers therefore provide only a rough estimate of the frequency of occurrence of the noun and verb forms of the stems. Nevertheless, the frequencies differed between the one- and two-step conditions. In the 
two-step group, 34/36 items had higher noun than verb frequencies. In the one-step group, 18/36 words had higher noun than verb frequencies (we return to this difference in the analysis section below). As expected, the two-step verbs had higher mean noun stem frequencies than the one-step verbs $(p<.01)$ and the one-step verbs had higher mean verb stem frequencies than the two-step verbs $(p<.05)$. The action ratings showed a positive correlation with the verb-stem frequencies $(r=.38, p<.001)$ and a negative correlation with the noun-stem frequencies $(r=-.51, p<.001)$.

Importantly, surface stem frequencies for the experimental words were matched using the Bank of English database. Stem frequency is the summed frequencies of all words in which the stem occurs irrespective of word class (i.e. lemma frequency). The whole word forms (stem+ing) were also matched on a number of frequency measures (CELEX written and spoken counts and the Bank of English spoken counts per million (Järvinen, 1994).

The target word sets (full -ing forms) were also matched on concreteness and imageability ratings each collected from 20 different participants using rating questionnaires. The questionnaires consisted of the experimental items along with filler words, and were identical apart from the instructions: for concreteness ratings, participants were asked to rate each word according to the extent to which they refer to concrete objects on a scale from 1 to 9 , when 9 represented "very concrete". For imageability ratings, participants were asked to rate the same words according to how well they elicited some sensory experience (mental image, smell, etc.) on a scale from 1 to 9 , where 9 represented "very imageable". None of the participants who took part in the rating pretests completed both questionnaires or were tested in the main experiment.

Finally, the experimental word sets were matched as closely as possible for a number of other factors that can affect lexical recognition: word-length (in terms of both 
number of letters and phonemes), bigram and trigram frequency, and orthographic, phonological and morphological neighbourhood size taken from the CELEX database (Baayen, 1995), using N-Watch software (Davis, 2005).

In addition, two lists of semantic primes were created, one for each list of morphological targets (See Appendix 1). Semantic relatedness ratings for the semantic primes and their target words were collected from 20 participants using questionnaires similar to those described above. The one-step and two-step verb stems and their potential semantic primes were tested in pairs (e.g., boat - rowing), as these were the forms to be used as primes and targets in the experiment. They were presented along with unrelated filler word pairs. Participants were asked to rate each word pair according to the extent to which they had similar meanings on a scale from 1 to 9 , when 1 represented "not very close in meaning" and 9 represented "very close in meaning". Semantic primes were selected such that the one-step and two-step pairs had average ratings of 6.7 and 6.5 respectively, and the groups did not significantly differ $(p>.1)$. The semantic prime words were also matched to the full -ing forms of the targets on length in phonemes and letters, log bigram and trigram frequency, orthographic and phonological neighborhood size, and on base form frequency (all ps>.1). 


\section{Table 1}

Means of matched variables for the complex experimental words (-ing forms) for both morphological conditions. Significant differences between conditions are marked with an asterisk.

\begin{tabular}{|c|c|c|c|}
\hline & One-step & Two-step & Significance \\
\hline Action rating & 6.7 & 3.3 & $*<.0001$ \\
\hline Verb stem freq & 1.1 & 0.4 & $* 0.02$ \\
\hline Noun stem freq & 2.1 & 6.7 & $* 0.002$ \\
\hline Surface stem frequency $(\mathrm{BE})$ & 7.3 & 10.3 & 0.16 \\
\hline Word form frequency $(\mathrm{BE})$ & 0.6 & 0.4 & 0.09 \\
\hline Word form freq (CELEX written) & 2.2 & 1.5 & 0.14 \\
\hline Word form freq (CELEX spoken) & 0.7 & 0.3 & 0.05 \\
\hline Concreteness rating & 4.8 & 5.2 & 0.07 \\
\hline Imageability rate & 5.4 & 5.6 & 0.66 \\
\hline Log bigram freq & 2.8 & 2.8 & 0.60 \\
\hline Log trigram freq & 2.0 & 2.0 & 0.99 \\
\hline Orthographic Neighbourhood & 2.6 & 2.5 & 0.93 \\
\hline Phonological Neighbourhood & 6.1 & 6.8 & 0.53 \\
\hline Morphological Neighbourhood & 7.3 & 8.7 & 0.06 \\
\hline No. of phonemes & 5.8 & 5.5 & 0.05 \\
\hline No. of Letters & 7.6 & 7.4 & 0.38 \\
\hline
\end{tabular}


Design. The uninflected stems were used as targets for lexical recognition and the full forms served as the masked primes. The stems were paired with their morphologically and semantically related primes and the morphological primes for the one-step targets served as the unrelated primes for the two-step targets, and vice versa.

The experiment included 144 filler words as targets, as well as 216 nonwords, for the purposes of the lexical decision task. The fillers were either monomorphemic or morphologically complex real words of varied length, in order to prevent the participants from developing any strategies of predictions based on the length and complexity of the experimental item. The nonwords were phonologically valid meaningless forms of varied length. Similar to the experimental items, the filler and nonword items were paired with a prime word, in order to create a similar visual event across all types of stimuli. Half of the fillers were paired with real word primes, and half with non-word primes, and this pairing was also applied to the nonwords.

Three experimental versions were created, in which all target words appeared only once. In each version, 12 targets from each morphological condition were assigned to one of the three priming conditions. This assignment was rotated across versions. Each version also included the same 144 filler words and the 216 nonwords. The experimental, filler words and non-word targets were pseudo-randomised, and the pseudo-randomisation order was kept constant across the three versions. Each version was divided into three blocks of one hundred trials, comprising 4 items per condition, 24 filler items and 72 nonword items. The three blocks were rotated creating three running orders for each version. 


\section{Procedure.}

Participants were tested in groups of no more than four. They were seated in a sound attenuated room in separate booths facing individual 17" CRT monitors and reaction time button boxes to record their responses. They were instructed that they would see string of letters on the screen and that they should press a button to signal whether it was an English word or not. They were asked to respond as quickly and accurately as possible. Participants always made yes responses with their dominant hand.

Each trial started with a fixation point $(*)$, which appeared centered on the screen for 500ms. The fixation point was followed by a visual mask (\#\#\#\#\#\#) which also appeared for $500 \mathrm{~ms}$. The prime word was presented in lowercase immediately after followed by the target word which was presented in uppercase and remained on the screen for $1500 \mathrm{~ms}$. All stimuli were presented in white, 18 point arial monospace font on a black screen.

The prime duration was $33 \mathrm{~ms}$ for Experiment 1, $200 \mathrm{~ms}$ for Experiment 2 and $300 \mathrm{~ms}$ for Experiment 3. For the longer prime durations, when the prime is usually visible to the participant, they were instructed to respond to the uppercase target word, which was visible for longest. Nothing else differed between experiments. Participants were allowed a break between blocks and the experiment lasted approximately 15 minutes.

Participants. Fifty undergraduate students participated in each experiment.

Participants were recruited from within the School of Psychology at the University of Birmingham and were awarded with course credit. They all had normal or corrected-to- 
normal vision and no language or reading impairments. No participant took part in more than one of the three experiments. The research was covered by University of Birmingham ethical approval ERN_10-1013.

\section{Results}

Two target words were excluded from Experiments 1 and 2 due to error rates of over 30\% (churn \& delve) and an additional target word was excluded from Experiment 3 (con). The remaining experimental trials were coded as correct or participant error.

The data from each experiment were subjected to a minimal outlier trim (by-subjects 2.5 standard deviation), resulting in the loss of a further 41 data points from Experiment 1 , 45 from Experiment 2, and 41 from Experiment 3. Two participants were replaced due to unprimed error rates over 30\% (one from Experiment 2 and one from Experiment 3).

Only participant errors were included in the error analysis and only correct trials were included in the RT analysis. The resulting mean RTs, standard deviations and percentage error rates are shown in Table 2. The effects of morphological and semantic priming (Control-Primed) are shown in Figure 1. As can be seen, most facilitation was observed in the morphological priming conditions, with semantic priming showing smaller effects. Percentage error rates were low and did not vary much as a result of priming.

The RT data were submitted to a linear mixed model analysis (Baayen, 2008). Reaction times were log-transformed. Subject and Item were entered as random effects using the statistical package $R$ and the corresponding package $l m e 4$ for mixed effects modeling. Sum-coding was applied to our fixed effects and the optimal random effect structure was determined through model comparison using likelihood ratio tests (Bates, 
Kliegl, Vasishth, \& Baayen, 2015). Through model comparison, it was established that a model containing random intercepts for Subject and Item, as well as by-item and bysubject random slopes for Priming provided the best fit for our data. The following variables were defined as fixed effect factors: SOA (33ms, 200ms, 300ms), Morphology (One-step, Two-step), Priming (Morphological, Semantic, Unrelated). Even though these measures were matched between conditions (see Table 1), we also included a measure of whole word frequency (BE word frequency), orthographic neighborhood size, and word length (Number of letters) in our models to assess their contribution to the effects observed. The three-way interaction between SOA, Morphology and Priming reached significance at $\chi^{2}(4)=12.189, \mathrm{p}<.05$. Separate models for each SOA are described below. 
Table 2

Mean reaction times, standard deviation and percentage error rates for the masked priming conditions of Experiments 1 to 3 .

\begin{tabular}{lllll}
\hline & One-Step & SOAK & Two-Step & BOAT \\
\hline Prime condition & RT (S.D.) & \% err & RT (S.D.) & \% err \\
\hline
\end{tabular}

Prime duration $33 \mathrm{~ms}$

\begin{tabular}{lcccc}
\hline $\begin{array}{l}\text { Morphological } \\
\text { soaking/boating }\end{array}$ & $519(107)$ & 3.9 & $501(90)$ & 4.6 \\
\hline $\begin{array}{l}\text { Semantic } \\
\text { wetting/rowing }\end{array}$ & $530(105)$ & 6.5 & $523(90)$ & 6.0 \\
\hline $\begin{array}{l}\text { Unrelated } \\
\text { bossing/thirsting }\end{array}$ & $539(108)$ & 4.5 & $531(100)$ & 5.4 \\
\hline
\end{tabular}

Prime duration $200 \mathrm{~ms}$

\begin{tabular}{lcccc}
\hline $\begin{array}{l}\text { Morphological } \\
\text { soaking/boating }\end{array}$ & $496(116)$ & 3.2 & $501(121)$ & 5.3 \\
\hline $\begin{array}{l}\text { Semantic } \\
\text { wetting/rowing }\end{array}$ & $547(132)$ & 8.3 & $539(125)$ & 8.3 \\
\hline $\begin{array}{l}\text { Unrelated } \\
\text { bossing/thirsting }\end{array}$ & $557(130)$ & 7.7 & $540(136)$ & 7.3 \\
\hline
\end{tabular}

Prime duration $300 \mathrm{~ms}$

\begin{tabular}{lcccc}
\hline $\begin{array}{l}\text { Morphological } \\
\text { soaking/boating }\end{array}$ & $495(126)$ & 4.6 & $493(108)$ & 3.7 \\
\hline $\begin{array}{l}\text { Semantic } \\
\text { wetting/rowing }\end{array}$ & $544(119)$ & 7.7 & $543(120)$ & 5.6 \\
\hline $\begin{array}{l}\text { Unrelated } \\
\text { bossing/thirsting }\end{array}$ & $557(123)$ & 8.9 & $557(130)$ & 7.3 \\
\hline
\end{tabular}


One-step: soaking-SOAK

Two-step: boating-BOAT

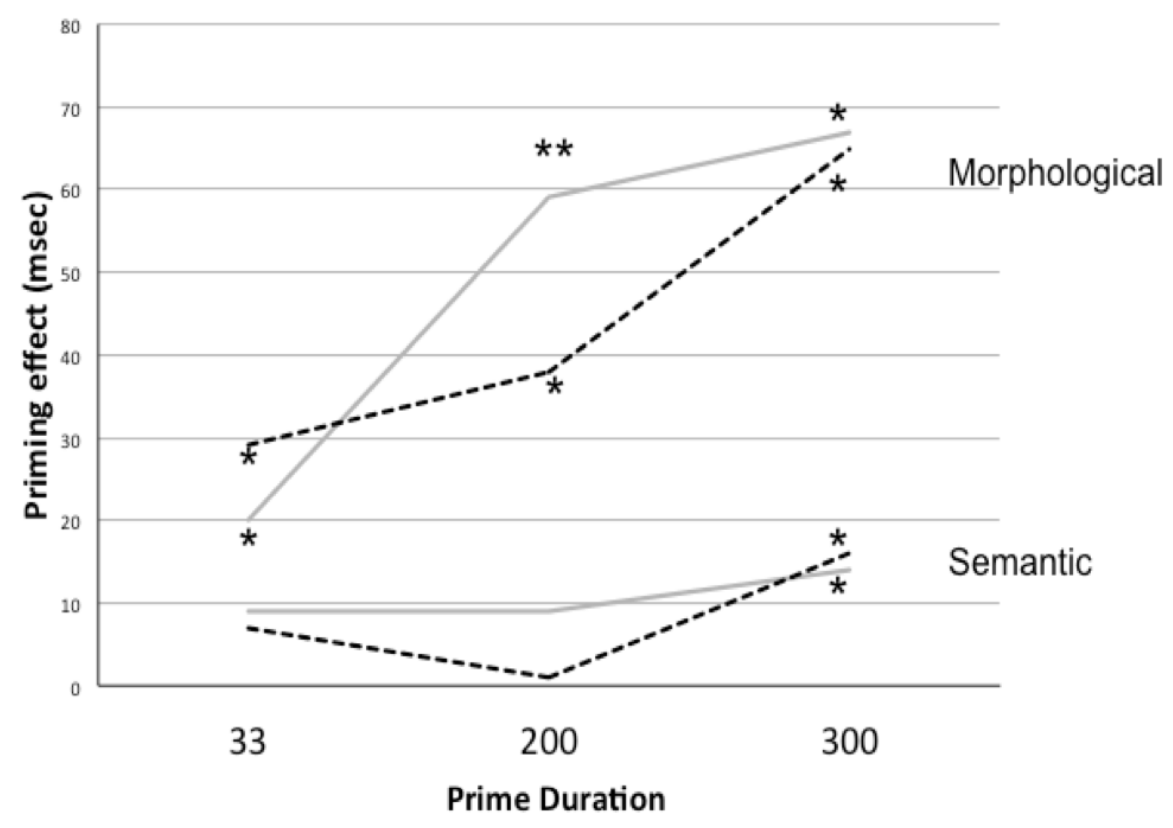

Figure 1. The effects of morphological and semantic priming (control-primed) for one and two-step stimuli at the three different prime durations in Experiments 1 to 3 . Significant effects are marked with asterisks.

Experiment 1: SOA 33. Again, the same procedures for model selection were followed as above, resulting in a random effect structure with random intercepts for Subjects and Items. We found the main effect of Priming to be significant at $\chi^{2}(2)=$ $58.314, \mathrm{p}<.0001$. Neither the main effect of Morphology, nor its interaction with Priming reached significance. The only other main effect to reach significance was $B E$ word frequency at $\chi^{2}(1)=9.9473, \mathrm{p}<.01$. No other main effects or interactions containing our lexical variables were significant. Tukey-adjusted pairwise comparisons between the different levels within the factor Priming were computed using the package lsmeans and are shown in Table 3. 


\section{Table 3}

Tukey-adjusted pairwise comparisons between the different levels within the factor Priming for Experiment 1: prime duration 33ms.

\begin{tabular}{lllll}
\hline Comparison & Est. & Std. Error & t-value & p-value \\
& & & & \\
\hline Morph vs. Semantic & -0.013741 & 0.002701 & -5.088 & $<0.0001$ \\
\hline Morph vs. Unrelated & -0.020175 & 0.002686 & -7.512 & $<0.0001$ \\
\hline Semantic vs. Unrelated & -0.006435 & 0.002701 & -2.382 & 0.05 \\
\hline
\end{tabular}

At $\mathrm{SOA}=33$, only a marginally significant effect of semantic priming is observed. In contrast, the effect of morphological priming is significant compared to both unrelated and semantic priming. Moreover, morphological priming is unaffected by the morphological complexity of the priming during this early stage of processing as all complex primes lead to equal activation of the stem through affix-stripping.

For the binomial error data, we carried out a generalized linear mixed-effects analysis with a logistic linking function, using the same model structure as for the RTs. The maximally random model did not converge and the random structure was simplified by removing the same interaction as for the main RT analysis. The only significant factor was Priming Contrast 2 (Morphological versus Semantic) due to the higher error rates in the semantic priming compared to the morphological priming condition (see Table 2). No other factors or interactions were significant.

Experiment 2: SOA 200. Mean RTs, standard deviations and percentage error rates are given in Table 2 and the priming effects are shown in Figure 1. The same procedures as in Experiment 1 were applied for data analysis. The optimal model following Bates et 
al. (2015) contained random intercepts for both Subjects and Items and by-item and bysubject random slopes for priming. By comparing models with and without the relevant fixed factor, we found that the factor Priming was significant at $\chi^{2}(2)=64.181, \mathrm{p}<$ .0001. BE word frequency also had a significant effect on reaction times $\left(\chi^{2}(1)=\right.$ 10.964, $\mathrm{p}<.001)$. The main effect of Morphology failed to reach significance while the interaction between Morphology and Priming showed significance at $\chi^{2}(2)=8.4378, \mathrm{p}$ $<.05$. None of our lexical variables (BE word frequency, Orthographic family size or number of letters) showed any significant interactions. Importantly, the critical interaction between Morphology and Priming survived the inclusion of our lexical variables. Given the significant interaction between Morphology and Priming, we established pairwise comparisons for the priming effect using the $R$ package lsmeans. Tukey-adjusted pairwise comparisons and their results are given in Table 4 for one-step and two-step derived items. P-values were computed using Satterthwaite approximations for the computation of degrees of freedom.

\section{Table 4}

Tukey-adjusted pairwise comparisons between the different levels within the factors Morph and Priming for Experiment 2: prime duration 200ms.

\begin{tabular}{lllll}
\hline Morph 1-step & & & \\
\hline Comparison & Est. & Std. Error & t-value & p-value \\
\hline Morph vs. Semantic & -0.042326 & 0.005735 & -7.380 & $<0.0001$ \\
\hline Morph vs. Unrelated & -0.052072 & 0.005151 & -10.109 & $<0.0001$ \\
\hline Semantic vs. Unrelated & -0.009746 & 0.005349 & -1.822 & 0.17 \\
\hline Morph 2-step & & & & \\
\hline
\end{tabular}




\begin{tabular}{lcccc}
\hline Morph vs. Semantic & -0.033176 & 0.005640 & -5.883 & $<0.0001$ \\
& & & & \\
\hline Morph vs. Unrelated & -0.032033 & 0.005029 & -6.370 & $<0.0001$ \\
\hline Semantic vs. Unrelated & 0.001142 & 0.005206 & 0.219 & 0.97 \\
\hline
\end{tabular}

As evident in Table 4, for both one-step and two-step derived items, only the morphological condition gave rise to a priming effect. Purely semantically related items did not show facilitation relative to an unrelated baseline. Moreover, a direct comparison of the priming effects between one-step and two-step derived items (Morph vs. Unrelated) showed a significant interaction $\left(\chi^{2}(1)=8.6435 \mathrm{p}<.01\right)$ : One-step derived morphologically related items primed their stem significantly more than two-step derived items.

The error data were again analysed using the same model structure with a logistic linking function. The maximally random model converged and this model yielded a significant main effect for Priming Contrast 2 (Morphological versus Semantic) due to the higher error rates in the semantic priming compared to the morphological priming condition. The interaction of Priming Contrast 1 (Unrelated versus Morphological and Semantic) with Morphology was also significant due to the greater overall decrease in error rates due priming for the one-step stimuli.

Experiment 3: SOA 300. The results are again shown in Table 2 and Figure 1. As can be seen, a large effect of morphological priming was observed as well as a smaller effect of semantic priming. The size of the priming effects does not differ for the oneand two-step stimuli. Percentage error rates were similar to Experiment 2 and showed a similar pattern to the RTs.

The same procedure for data analysis as for Experiments 1 and 2 was conducted. 
Through model comparison, a random effect structure with random effects for Morphology and Priming, as well as by-item and by-subject random slopes for Priming was found to provide the best fit for our data. Only the main effects of Priming and $B E$ word frequency had a significant effect on the log-transformed data (Priming: $\chi^{2}(2)=$ 80.751, $\mathrm{p}<.0001 ;$ BE word frequency: $\left.\chi^{2}(1)=12.613 ; \mathrm{p}<.001\right)$. No other main effects or interactions reached significance. Tukey-adjusted pairwise comparisons between the different levels within the factor Priming were carried out and the results of these comparisons are given in Table 5.

\section{Table 5}

Tukey-adjusted pairwise comparisons between the different levels within the factor Priming for Experiment 3: prime duration 300ms.

\begin{tabular}{lllll}
\hline Comparison & Est. & Std. Error & t-value & p-value \\
\hline Morph vs. Semantic & -0.043480 & 0.005054 & -8.603 & $<0.001$ \\
\hline Morph vs. Unrelated & -0.054652 & 0.004530 & -12.064 & $<0.001$ \\
\hline Semantic vs. Unrelated & -0.011172 & 0.004333 & -2.578 & 0.03 \\
\hline
\end{tabular}

Unlike the pattern observed in Experiment 2, no modulation of the degree of priming was observed at $\mathrm{SOA}=300$. Both one-step and two-step derived items primed their stems equally well.

The maximal model converged for the analysis of the error data. Errors showed significant effects for both Priming contrasts and no interactions with Morphology. 


\section{Discussion}

The masked priming experiments yielded different patterns of effects for morphological and semantic primes across the three prime durations. As predicted, we observed a significant facilitatory effect of morphological priming compared to both Semantic and Control conditions at this brief prime duration. There was also no difference in the size of morphological priming between the one- and two-step verbs. The effect of semantic priming observed was only borderline significant. These results are consistent with a pre-lexical $\{$-ing $\}$ stripping process that proceeds in a similar way in the two morphological conditions and is therefore unaffected by covert morphological complexity. Significant semantic priming also failed to occur at a prime duration of $200 \mathrm{~ms}$, at which the primes were visible to the participants. This may have been due to the relative low frequency of our primes. Importantly however, despite the lack of significant semantic priming, differential effects of morphological priming were observed. One-step verbs primed their stems significantly more than two-step verbs.

Significant effects of semantic priming did emerge, at a prime duration of $300 \mathrm{~ms}$, and the effects were similar for both one- and two-step stimuli. Crucially, the interaction of morphological priming and derivational depth disappeared when semantic processing of the primes came into play, demonstrating that the purely semantic relationship between our primes and targets is the same for the two morphological conditions. However as mentioned in the introduction, recent accounts of morphological effects take an approach which directly maps form onto meaning and does not represent word structure (e.g., Baayen et al., 2011). Potential "amorphous" accounts of our findings relate to frequency and semantic relationships between our stems and derived 
forms and we investigate these below.

Investigating interactions with stem frequency. Our key finding was unaffected by our measures of word and stem frequency. Whole word frequency significantly affected reactions times in all three experiments but did not interact with the factors of morphology or priming. Most importantly, whole word frequency did not modulate the asymmetric pattern of priming observed at SOA 200.

However, as mentioned in the Methods section, there was a difference between our one- and two-step verb groups in the ratio between noun-stem and verb-stem frequency. In particular there were more items in the one-step group than in the twostep group with higher verb-stem than noun-stem frequencies. It is possible therefore, that our effect is due to initial access of the most "prototypical" or most frequent base form following stripping of the suffix and that, in the case of the two-step items, this most frequently is a noun. If this results in conflict with the verb suffix -ing, then a verb stem must consequently be retrieved. In order to test whether the interaction of morphology and priming observed could be attributed to differences in derivational depth and not simply to the 'prototypicality' or frequency of occurrence for a given stem as a noun or verb, we conducted a follow-up analysis that only contained those items with higher noun than verb frequencies in both verb groups. The patterns observed remained the same as reported above, and this item subset again yielded a significant interaction of morphology and priming, suggesting that our effects are not reducible to the frequency or 'prototypicality' of a given stem as a particular lexical category. However, this analysis only includes a subset of the available data by focusing on items with higher noun frequencies, we therefore ran another follow-up analysis on the data for SOA 200 to investigate the 'prototypicality' hypothesis ${ }^{1}$. In this analysis, 
the notion of derivational depth (One-step vs. Two-step) was abandoned altogether. Instead, we carried out a factorial design using the factors Priming (Morphological, Semantic, Unrelated) and Prototypicality (Higher noun frequency item vs. Higher verb frequency item). The random effect structure included random intercepts for both Subjects and Items, as well as by-item and by-subject random slopes for Priming. The interaction between Priming and Prototypicality did not reach significance $(\mathrm{p}>.3)$. This indicates that the patterns observed in an account based on frequency-coding are different from an analysis that incorporates a distinction between one-step and two-step derived items. While the prototypicality hypothesis may be more parsimonious, it does not capture an additional difference between our experimental items, namely the depth of their derivation that interacts with the factor Priming. Therefore, we see that for an SOA of $200 \mathrm{~ms}$, priming effects are neither reducible to affix-stripping, nor to an account based on frequency-coding. Instead, priming effects appear to be modulated by the depth of derivation of the relevant morphologically complex word.

Investigating interactions with semantics. We argue that the asymmetrical priming pattern observed at $200 \mathrm{~ms}$ cannot be attributed to a non-morphological semantic difference between the one-step and two-step words because the purely semantic primes had no significant effect at this prime duration. Of course, derivational differences in the word class of the stem can have concomitant effects on semantics, as the semantics of nouns and verbs clearly differ. This means that for morphologically related pairs, the semantic similarity between prime and target cannot easily be distinguished from their morphological processing in terms of distance to the stem i.e., their derivational depth. In other words, the closer the affixed form is to the stem, the more quickly their semantic relationship can be processed. It is possible therefore that semantic rather than 
morphological relationships determine the difference in morphological priming observed at SOA 200. Following a suggestion by a reviewer ${ }^{2}$ we included the continuous variable 'semantic similarity' into the model for Experiment 2. To do this, we used pretrained vector representations of words as calculated by word $2 \mathrm{vec}$ (https://code.google.com/archive/p/word2vec/), a tool which uses continuous bag-ofwords and skip-gram architectures to compute vector representations of words (McCormick, 2016). The cosine similarity between our prime and target vectors provided a new continuous variable, Semantic Similarity. We then created a new model with Morph and Priming as fixed factors, as well as the centered continuous variables Semantic similarity, BE word frequency, Orthographic family size and Number of Letters. In this model, the critical interaction between Morphology and Priming is no longer significant $(p>0.1)$. With regard to this finding, an important point concerns whether or not word class is factored in during the computation of semantic similarity. It is worth noting that architectures such as bag-of-word that are used by word2vec to produce vector representations of words, do not account for different morphological word classes. In particular they do not differentiate between $\operatorname{boat}(\mathrm{V})$ and $\operatorname{boat}(\mathrm{N})$ or between $\operatorname{soak}(\mathrm{V})$ and $\operatorname{soak}(\mathrm{N})$, a distinction that is crucial for our theory. We are therefore left with the difficulty of potential semantic contributions to a derivational account of our effect and conversely with potential derivational contributions to an amorphous semantic account of our effect. It is worth noting that architectures such as bag-of-word that were used here by word2 vec to produce vector representations of words, do not account for different morphological word classes. In particular they do not differentiate between boat $(\mathrm{V})$ and boat $(\mathrm{N})$ or between $\operatorname{soak}(\mathrm{V})$ and $\operatorname{soak}(\mathrm{N})$, a distinction that is crucial for our theory. In future studies, it will therefore be particularly insightful to implement this distinction by incorporating an additional corpus pre- 
processing step. In this step, a POS-tagger would be run on the corpus in order to classify every occurrence of, for instance, boat as either boat(V) or boat(N). Running word2vec on this annotated corpus would yield two separate vectors (e.g. boat(V) and boat $(\mathrm{N}))$ and allow us to assess potential semantic contributions to a derivational account or conversely potential derivational contributions to an amorphous interpretation of our effect.

However, when semantic priming effects do emerge more strongly at a prime duration of $300 \mathrm{~ms}$, the asymmetry in the effect of morphological priming for 1-step and 2-step verbs is no longer evident. This aspect of our pattern of results is more problematic for a purely semantic account of our priming effects. If the asymmetry observed at prime duration $200 \mathrm{~ms}$ is due to differences in the semantic relationship between primes and targets, one would expect it to survive - or even increase - at a prime duration of $300 \mathrm{~ms}$ when the primes can be fully processed prior to target onset and when semantic priming is observed. This is not what we observe. Instead, we propose that our pattern of results is consistent with a process in which our one- and two-step stimuli get to the same place in terms of their lexical-semantics but where our one-step verbs get there faster due to their more direct derivational path.

Nevertheless, the issue of the contribution of semantics to our results remains controversial (e.g., Baayen et al, 2011). The final experiment we describe was therefore designed to test the relationship between derived and base forms of our one- and twostep verbs in a paradigm that has been shown to be insensitive to semantic relationships.

\section{Experiment 4}

The aim of this experiment was to look for further evidence of effects of covert 
derivational complexity on visual word processing. We have proposed that the processing of a morphologically complex word is affected by its relationship to the base form. We tested this claim using a delayed priming paradigm, which has been shown to isolate effects of morphological processes (Bentin \& Feldman, 1990; Napps, 1989; Bozic, et al, 2007; Lahiri \& Reetz, 2010, Schuster \& Lahiri, 2018). On each trial of this task, participants are presented with a word for lexical decision and prime and target words are separated by a number of intervening trials. Because the base forms are zeroderived, the correct root will be given in a minimal phrase. Thus, in the morphological conditions, soaking will be primed by to soak and a soak and boating will be primed by to boat and a boat (see Table 6).

\section{Table 6}

Examples of the experimental target words and their primes in the three priming conditions of Experiment 4.

\begin{tabular}{llll}
\hline Priming Conditions & Noun phrase & Verb phrase & Unrelated \\
\hline Morphological conditions & & & \\
\hline One step soaking & a soak & to soak & a/to cheat \\
\hline Two step boating & a boat & to boat & a/to drum \\
& & & \\
\hline
\end{tabular}

Delayed priming differs from masked priming in that it measures long-term lexical and morphological activation and does not tap into the time-course of word processing in the same way as the masked priming paradigm. Arguably, morphological priming effects in this paradigm will be influenced by derivational processes occurring during prime as well as target processing. Nevertheless, if the amount of priming 
observed is dependent on the derivational relationship between the derived and stem forms, then we should observe significantly different patterns of priming for the oneand two-step complex words. This is because for the one-step items, there is a direct relationship between the base and the -ing form (e.g. to soak-soaking) while the noun base prime (a soak) does not form part of the derivation of soaking. In contrast, both noun and verb forms of the two-steps are a necessary part of the direct derivational chain of the -ing form (e.g. a boat $(N)>$ to boat $(V)>$ boating).

\section{Method}

Materials \& Design. The experimental materials were the same as those used in Experiments 1 to 3, except that the full -ing forms served as the target items. For each target word (e.g., soaking), two prime phrases were constructed which would elicit either a nominal or verbal reading of the verb stem (e.g. a soak, to soak). In addition, a monosyllabic control verb was selected for each target word (see Appendix 2). All control words were semantically, morphologically and phonologically unrelated to the targets but matched to them for both whole -ing form and stem frequencies. They were also matched in length to the experimental word stems in terms of number of phonemes and letters. Half of the control words for each morphological condition appeared in a noun phrase and half appeared in a verb phrase (See Appendix 2). Each group of 36 experimental and control items was then divided into three subsets of 12 items for assignment to conditions across participants.

Design. Each target word occurred in the three priming conditions shown in Table 6. For a given participant, each matched subset was assigned to a different condition, so 
that each participant responded to each experimental word only once. The assignment of word sets to priming conditions was rotated across participants so that each target occurred in each priming condition an equal number of times.

Prime and targets pairs (144 trials) were separated by lags of 5, 6 or 7 fillers, with equal numbers of pairs in each morphological condition assigned to the three lags (432 intervening filler trials in total). The intervening fillers trials were a mixture of 'a/the' and 'to' phrases and non-phrases (e.g. the work, to *blar), nonwords plus -ing (e.g., *pilting), real words with other affixes (e.g., unhappy, squeamish) and morphologically simple words of different lengths. A further 60 similar filler items were included to further vary the distance between prime and target sequences and prevent participants from being able to anticipate related items. Of the resulting 636 trials, half were words and phrases and half were nonwords or non-phrases with equal numbers of each word or phrase type in each group.

The experiment consisted of six blocks of 106 trials. Each block contained six prime-target sets from each morphological word group, two of each occurring in one of the three priming conditions. The experiment started with a practice block of 20 trials, similar in form to the experimental blocks. To control for practice effects the order of the blocks was also rotated across participants.

Procedure. Participants were run in groups of eight seated in a separate booth, in front of individual 17" CRT monitors and reaction time button boxes to record their responses. "Yes" and "No" buttons were placed such that the "Yes" response button was pressed by the participant's dominant hand. Reaction times and response accuracy were recorded. Each trial began with a $50 \mathrm{~ms}$ bleep followed by a $500 \mathrm{~ms}$ pause. The visual stimulus was then presented for 500ms and subjects responded by making a button press 
lexical decision. There was a 'no response' timeout of $2000 \mathrm{~ms}$, otherwise a $1600 \mathrm{~ms}$ inter-trial interval followed the participant's push button response. Reaction time was measured from the onset of the visual stimulus and errors were recorded.

Participants. Sixty adult native British English speakers were tested, drawn mostly from the undergraduate population of the University of Oxford. Participants had no history or evidence of dyslexia, had normal or corrected-to-normal vision and were paid for their participation.

\section{Results}

One participant was replaced due to high mean error rates (more than 20\%) and one participant was removed from the analysis due to high data loss from technical errors. For the 59 remaining participants, all experimental trials were coded as correct $(n=3673)$, participant error $(n=213)$ or technical error $(n=361)$. A by subjects 2.5 S.D. trim of the data resulted in a loss of a further 45 data points. The resulting mean RTs, standard deviations and percentage error rates are shown in Table 7. As can be seen, facilitation was observed in all priming conditions. For the two-step targets, noun and verb phrase primes yielded equal amounts of facilitation. In contrast, verb phrase primes facilitated one-step targets more than noun phrase targets. Percentage error rates were consistently lower in all primed conditions.

\section{Table 7}

Mean response latencies, standard deviations (ms) and percentage error rates are shown for one-step and two-step verbs in the three priming conditions of Experiment 4. The 
effect of priming (unrelated-related) is also shown. Significant effects are marked with an asterisk.

\begin{tabular}{lllllll}
\hline & One-Step & Soaking & & Two-Step & Boating & \\
\hline Prime & $\begin{array}{l}\text { RT } \\
\text { (S.D.) }\end{array}$ & \%err & Priming & $\begin{array}{l}\text { RT } \\
\text { (S.D.) }\end{array}$ & \% err & Priming \\
\hline $\begin{array}{l}\text { Noun Phrase } \\
\text { a soak/a boat }\end{array}$ & $588(140)$ & 2.5 & $33^{*}$ & $585(138)$ & 4.2 & $37^{*}$ \\
\hline $\begin{array}{l}\text { Verb Phrase } \\
\text { to soak/to boat }\end{array}$ & $567(131)$ & 2.5 & $54^{*}$ & $588(135)$ & 3.4 & $34^{*}$ \\
\hline $\begin{array}{l}\text { Control } \\
\text { a cheat/a drum }\end{array}$ & $621(147)$ & 8.6 & & $622(144)$ & 10.6 & \\
\hline
\end{tabular}

The RT data were again submitted to a linear mixed model analysis using the same procedure as in Experiments 1-3. Through model comparison, we found a random effect structure with random intercepts for Morphology and Priming to provide the best model fit. The lexical variables BE word frequency, Number of letters and Orthographic family size were also included to ascertain their contribution to the effects observed. Only Priming and BE word frequency were significant as main effects (Priming: $\chi^{2}(2)=$ 115.33, $\mathrm{p}<.0001 ;$ BE word frequency: $\left.\chi^{2}(1)=16.867, \mathrm{p}<.0001\right)$. In addition to this, the interaction between Morphology and Priming reached significance at $\chi^{2}(2)=9.221, \mathrm{p}<$ .01 and survived the inclusion of our lexical variables. No other main effects or interactions were significant.

In view of the significant interaction between Morphology and Priming, followup comparisons were established within one-step and two-step derived items. The results are given in Table 8 .

\section{Table 8}

Tukey-adjusted pairwise comparisons between the different levels within the factors Morph and Priming for Experiment 4. 


\begin{tabular}{lllll}
\hline Comparison & Est. & Std. Error & t-value & p-value \\
\hline Morph 1-step & & & & \\
\hline NP vs. VP & 0.013187 & 0.004152 & 3.176 & $<0.01$ \\
\hline NP vs. Unr & -0.025378 & 0.004232 & -5.997 & $<0.001$ \\
\hline VP vs. Unr & -0.038565 & 0.004259 & -9.055 & $<0.001$ \\
\hline Morph 2-step & & & & \\
\hline NP vs. VP & & & & 0.818 \\
\hline NP vs. Unr & -0.002514 & 0.004163 & -0.604 & $<0.0001$ \\
\hline VP vs. Unr & -0.025575 & 0.004263 & -6.000 & $<0.0001$ \\
\hline
\end{tabular}

As can be seen in Table 8, there is no significant difference in priming between NP and VP for two-step derived items. For one-step derived items, on the other hand, the comparison between NP and VP yields a significant difference with NPs yielding longer reaction times.

The error data were again analysed with a logistic linking function. The maximally random structure converged and this model yielded only a significant effect for Priming Contrast 1 (control versus NP and VP). There were no interactions with Morphology.

\section{Discussion}

Experiment 4 was designed to test our claim that the processing of a morphologically complex word is affected by its derivational relationship to the base form. The delayed repetition priming paradigm has been shown to isolate effects of 
morphological overlap (Bentin \& Feldman, 1990; Napps, 1989; Bozic, et al, 2007;

Lahiri \& Reetz, 2010, Schuster \& Lahiri, 2018). We therefore predicted a difference in priming patterns across the two Morphological conditions for noun and verb primes. We observed no main effect of morphological condition. However, there was a main effect of priming and an interaction of priming and morphological condition. This interaction was due to the difference in priming patterns for the one-step and two-step verbs. For the two-step verbs, both the noun and verb forms primed to a similar extent. However, for the one-step verbs, the verb forms primed significantly more than the noun forms. The data therefore show the predicted difference in the pattern of priming effects for one-step and two-step complex words based on the word class of form-identical primes.

As mentioned above, delayed priming tests long-term activation and is not sensitive to the time course of morphological activation. Indeed, the pattern of priming effects observed are not transparently relatable to derivational depth, which would predict strongest priming from those phrases including stems closest in the derivational chain to the derived form (e.g., to soak-> soaking, to boat->boating) and no priming from phrases including stems which are not part of the derivation (e.g., a soak-soaking). This is not what we observed.

We do indeed see the strongest facilitation for the most direct derivational relationship i.e., when one-step verbs are primed by a VP (to soak - soaking). In this condition, the prime to soak would strongly activate the verb stem soak $(V)$, which would then facilitate the processing of the target soaking. Since the verb stem is the base form, the noun stem $\operatorname{soak}(N)$ would not be morphologically activated during prime processing. During target processing, the noun stem $\operatorname{soak}(N)$ would also not be activated as it does not form part of the derivation of soaking. 
In all other conditions however, the effect sizes we observe are the same. This aspect of the priming pattern was unexpected. However, an explanation is possible that is consistent with our claims regarding the underlying derivational chains. In all of these conditions, both noun and verb stems would be activated. For the one-step items primed by a NP, the prime a soak would result in activation of both the noun stem $\operatorname{soak}(N)$ and, by derivation, the base verb stem $\operatorname{soak}(V)$; that means both forms become activated during prime processing. When two-step items were primed by a NP, although the prime $a$ boat is a base noun and would not activate the verb stem boat $(V)$ during prime processing, the verb stem would be activated during target processing as it forms part of the derivation of boating, again resulting in the activation of both forms. Finally, for the two-step items primed by a VP, the prime to boat would also result in activation of both the verb stem $\operatorname{boat}(V)$ and, by derivation, the base noun stem $\operatorname{boat}(N)$.

Another unexpected aspect of our results is that the facilitation we observe is significantly weaker for those conditions in which both stem forms are arguably activated, either prior to and/or during target processing. A possible explanation of this pattern involves the activation of morphologically related lexical representations and some form of competition between these related forms. In other words, the activation by derivation of both noun and verb stems would slow access to the correct base form during target processing (e.g., de Jong, Schreuder \& Baayen, 2000). Such competition is lacking only in the case of the one-step verb priming condition in which the noun stem will not be activated.

\section{General Discussion}

We have reported four experiments that tested the processing of zero-derived 
verb forms such as soaking and boating, which differ in their derivational relationship to their base forms (stems). The difference is based on the combinatorial rule of English that $\{$-ing $\}$ is a suffix that can only be attached to verbs, and that the verb stem could itself be derived from a noun. Consequently, while the $\{$-ing $\}$ in boating must attach to the verb to boat, this verb originally comes from the noun boat. In contrast, soaking is derived by adding $\{$-ing $\}$ directly to its basic verb stem, to soak. Although the noun $a$ soak exists, it is not basic but derived from the verb. Thus, boating is a two-step derivation while soaking is a one-step derivation. Critically the difference between a one- and two-step derived verb form is not due to morphological complexity of their surface form. Neither is it due to the availability of noun and verb stems. Rather, we propose that the difference between the words is due to their underlying morphological complexity.

The larger priming effect for the one-step than two-step verbs in Experiment 2 (prime duration, 200ms) we argue is due to their direct derivational relationship to their stems. Early decomposition processes separate the suffix and the stem (e.g. soak+ing), however, at the lexical level the $\{$-ing $\}$ suffix signals the stem must be a verb and for the one-steps this matches the base form of their target stems directly. This is not true for the two-step verbs (boat+ing), which have an indirect relationship to their base nouns stems via the verb stem form.

We have also argued that the effects of underlying morphological complexity in the priming patterns that we have observed cannot be attributed to semantics alone. In Experiment 2, at a prime duration of $200 \mathrm{~ms}$, the one-step primes facilitated responses to their stems significantly more than the two-step primes. At this prime duration, no significant effects of semantic priming were observed. However, this difference did not survive the addition of a measure of semantic similarity between primes and targets to 
the analysis. A problem with the semantic similarity measures derived from corpora of this type is that they do not distinguish the grammatical class of zero-derived stems or items that are orthographically identical. This means that such measures do not factor out issues of morphological structure. The relationship between morphology and semantics is a complex one as morphological relationships between words can be built in several ways and these are not always reflected in the written language. For example, two words can be 'derived' from the same stem by virtue of some phonological process, which may not be overt in orthography. Pairs which are distinguished morphologically but not overtly in the orthography include $u s e[j u s]_{\mathrm{N}}$ vs. use [juz $]_{\mathrm{V}}$ (difference in voicing of consonants), 'permit( $N)$ vs. per 'mit( $V)$ (difference in stress) or zero derived such as kiss $(N)$ vs. $k i s s(V)$ (no phonological difference). All three examples are semantically transparent. But in order to estimate the semantic similarity, one needs to have the word class information. More discriminative corpus measures of semantic and morphological relationships are required in order to investigate this issue further.

Importantly for our position however, in Experiment 3, when semantic priming effects did emerge at a prime duration of $300 \mathrm{~ms}$, the effects were the same size for both the one- and two-step stimuli. This suggests that there were no significant differences in the strength of the semantic relationships between the primes and targets for the lowfrequency one- and two-step verbs we tested in our studies. Of course, this need not be true of all such items. The semantic similarity between an affixed form and a stem form may be additive in the sense that the closer the affixed form is to the stem, the more similar the two words are in meaning. That in fact, is the outcome of derivational suffixation. Thus, national is more similar to nation than nationality. Future research is required to differentiate the contributions of morphological structure and semantic relatedness to written word processing. 
Finally, in Experiment 4, which used a delayed priming methodology insensitive to semantic relationships, one-step targets were facilitated more by verb phrases than noun phrases, whereas two-step targets were facilitated equally by both prime types. These effects are not attributable to a difference in the semantic relationship between our primes and targets for our one and two-step stimuli. In the delayed priming experiment, although some activation due to shared semantics might occur, it should occur for all primes and would dissipate over the delay between prime and target trials (e.g., Bozic et al, 2007).

In contrast, no effects of covert morphological complexity were observed in Experiments 1 and 3, in which primes were exposed for $33 \mathrm{~ms}$ and $300 \mathrm{~ms}$ respectively. At the very short prime duration, the effect of morphological priming was the same for both one- and two-step items and only marginal semantic priming was observed. This pattern of results is consistent with the large body of research reviewed above, which provides evidence for an early process of morpho-orthographic decomposition that is blind to semantics (e.g., Rastle \& Davis, 2008; Rastle, et al., 2004). At the longest masked prime duration, significant effects of semantic priming were observed that were similar in size for both one- and two-step items. At this prime duration, the effects of morphological primes were of the same size and did not interact with derivational complexity. This pattern of results is consistent with studies showing that when primes are fully visible, the amount of priming observed is determined by the semantic relationship (e.g., Lavric et al., 2011). However, theories that incorporate only early morpho-orthographic decomposition followed by lexical-semantic verification (e.g., Lavric, et al, 2011; Lavric, et al., 2012; Rastle \& Davis, 2008; Rastle, et al., 2004; Whiting, et al., 2014) cannot account for the effects observed in Experiments 2 and 4. 
Our findings, in combination with Pliatsikas et al. (2014), are consistent with a model of complex word processing in which the output from a pre-lexical decomposition process is mapped onto a morphologically structured mental lexicon. The fMRI data showed significant differences in BOLD response for the one and twostep derived $\{$-ing $\}$ complex words (soaking versus boating). However, this finding provides no direct information about the underlying processing differences or about the nature of the relationship to the base noun and verb forms. Behavioural data were therefore required to unravel the differences. We found no main effects of Morphology in any experiment; nor did the direct responses to the one- and two-step $\{$-ing $\}$ forms in the control condition of Experiment 4 differ. There is therefore no evidence of any intrinsic differences in difficulty between the full $\{-i n g\}$ forms we tested. The pattern of facilitation we observed in Experiments 2 and 4 can also not be explained in terms of word length, orthographic neighbourhood, whole word frequency, or differences in noun and verb frequencies of the stems, none of which interacted with the interaction of morphology and priming.

We therefore propose that the differences in the fMRI data observed by Pliatsikas et al. (2014) and the priming patterns we report here must be attributable to differences in morphological processes across the two sets. The difference in effects for morphological primes in Experiment 2 suggests that following the decomposition of the prime the stems are marked as verbs, leading to greater priming for the one-step verb targets compared to the two-step noun targets.

The difference in complexity between our one and two-step words is based on the observation that our two-step words are derived from a noun stem and the combinatorial constraint that the suffix $\{$-ing $\}$ can only attach to verbs. Therefore, the processing of these words involves the activation of both noun and verb stems. We have 
shown that the additional complexity leads to increased activation in the LIFG.

Consequently, grammatically at least, nouns and verbs must be represented in the same place and processed in a similar fashion. Our explanation of our data also requires the storage of lexical grammatical information since otherwise there would be no explanation why boating is more complex than soaking (see Vigliocco, Vinson, Druks, Barber \& Cappa, 2011, for a review of this issue). This does not, of course, entail that all stems in all languages are specified for grammatical category. For example, it has been argued that Polynesian, Salish and Munda languages do not mark noun-verb distinctions (e.g., Evans, \& Toshiki, 2005; Foley, 2008; Kinkade, 1983). Even in English, in pairs like a guard and to guard, it is difficult to establish which is the basic form (Darby \& Lahiri, 2016). Our claim is not that every base form must be marked for word class, but that when they are, differential effects of morphological processing will be observed. However, our data do not allow us to claim that such derivational processes are automatically employed whenever complex words are encountered. Further research is required to test whether sentence contexts work to restrict such derivational processing.

Nevertheless, combinatorial morphological constraints exist in all languages. Even languages with minimal morphology, such as Mandarin, exhibit combinatorial constraints (e.g., Sproat \& Shih, 1992). Such constraints are not only used productively to process complex items as we have shown here, they are also used to create novel lexical items (cf. Schuster \& Lahiri (2018); Schuster et al. (2018). In this context, the knowledge that $\{$-ness $\}$ is a suffixal unit which creates nouns leads to active creation of compound like phrases such as sing-a-long-ness (see OED entry for $\{$-ness $\}$ ), for instance. Evidence from language change also suggests that knowledge of combinatorial constraints plays a role. In loans, complex words are usually borrowed as wholes (e.g., 
commencement which was borrowed around 1250 while the base commence was borrowed later (ca. 1330). However, once a morphological relationship was established, the suffix -ment began to be used in Germanic words, such as shipment (ca. 1802). This suggests that native speakers identified the use of -ment and actively extended it to other words.

However, we are still a long way from understanding the relationship between our representations of complex lexical items and our ability to generate and process legal novel words and at the same time recognise that certain forms must be illegal e.g., *rice-ing, *song-ing, *run-ize, *pasta-ing, *chair-ful, *un-bird, *matern-ity-ful, etc. Similarly, although pseudo-affixed forms such as corner prime corn in masked priming at early SOAs, we do not yet know whether at this point any form of combinatorial constraints are in operation. For example $\{$-er $\}$ can only be attached to verbs (writer, player) but corn is a noun. Our results suggest that these issues could be revisited in the light of such affixing constraints.

In summary, we have demonstrated that boating and soaking classes of words show different patterns of priming, which suggests that there are hierarchical structures represented, whereby $\operatorname{boat}(V)$ is derived from $\operatorname{boat}(N)$ while $\operatorname{soak}(V)$ is not derived from $\operatorname{soak}(N)$. These data are consistent with a process of affix-stripping during the processing of morphologically complex words but, importantly, one that is informed by the combinatorial constraints governing stems and affixes. In combination with the finding of Pliatsikas et al. (2014), we argue that our data are consistent with an independent level of morphological complexity that cannot be reduced to superficial morpho-orthographic complexity or to lexical semantics but which is informed by morphological combinatorial constraints. 


\section{Acknowledgments}

The study was funded by the ESRC (Project code: RES-000-22-4222). We would like to thank Laura Scholes and Arjun Sandher for running Experiments 2 and 3 at the University of Birmingham and Adam Roberts and Jeannique Darby for running Experiment 4 at the University of Oxford. We would also like to thank Jan Zandhuis for his technical support for the masked priming experiments.

\section{Footnotes}

1. We thank an anonymous reviewer for this suggestion.

2. This suggestion and the semantic similarity numbers were provided to us by Peter Hendrix. 


\section{References}

Aronoff, M. (1980). Contextuals. Language, 56(4), 744-758.

Baayen, R. H. (1995). The CELEX lexical database (release 2). Philadelphia, PA:

Linguistic Data. Baayen, R. H. (2008) Analyzing Linguistic Data. A Practical Introduction to Statistics Using R. Cambridge University Press.

Baayen, R. H. (2008) Analyzing Linguistic Data. A Practical Introduction to Statistics Using R. Cambridge University Press.

Baayen, R. H., Milin, P., Đurđević, D. F., Hendrix, P., \& Marelli, M. (2011). An Amorphous Model for Morphological Processing in Visual Comprehension Based on Naive Discriminative Learning. Psychological Review 118(3):438-81

Barber, H., Domínguez, A. \&, de Vega, M. (2002). Human brain potentials indicate morphological decomposition in visual word recognition. Neuroscience Letters, $318,149-152$.

Barr, D. J., Levy, R., Scheepers, C., \& Tily, H. J. (2013). Random effects structure for confirmatory hypothesis testing: Keep it maximal. Journal of Memory and Language, 68, 255-278

Bates, D., M. Maechler \& B. Bolker. 2012. Package 'lme4' [Documentation file, online]. Document last modified on June 23, 2012 (accessed on August 8, 2012). Available at http://cran.stat.sfu.ca/web/packages/lme4/lme4.pdf

Bentin, S., \& Feldman, L. B. (1990). The contribution of morphological and semantic relatedness to repetition priming at short and long lags: Evidence from Hebrew. The Quarterly Journal of Experimental Psychology Section A: Human Experimental Psychology, 42(4), 693-711. 
Boudelaa, S., \& Marslen-Wilson, W. D. (2005). Discontinuous morphology in time: Incremental masked priming in Arabic. Language and Cognitive Processes, 20, 207-260.

Bozic, M., Marslen-Wilson, W. D., Stamatakis, E. A., Davis, M. H., \& Tyler, L. K. (2007). Differentiating morphology, form, and meaning: Neural correlates of morphological complexity. Journal of Cognitive Neuroscience, 19(9), 1464-75.

Clark, E. V., \& Clark, H. H. (1979). When nouns surface as verbs. Language, 55(4), $767-811$.

Darby, J. and Lahiri, A. (2016) Covert morphological structure and the processing of zero-derived words. The Mental Lexicon 11:2.

Davis, C. J. (2005). N-Watch: A program for deriving neighborhood size and other psycholinguistic statistics. Behavior Research Methods, 37(1), 65-70.

Davis, M. H., van Casteren, M., Marslen-Wilson, W. D. (2003). Frequency effects in processing inflected Dutch nouns: A distributed connectionist account. in Baayen, R. H. \& Schreuder R. (Eds) Morphological Structure in Language Processing. Mouton de Gruyter, Berlin, p.427-462.

Davis, M. H., \& Rastle, K. (2010). Form and meaning in early morphological processing: Comment on Feldman, O’Connor, and Moscoso del Prado Martı'n (2009). Psychonomic Bulletin \& Review, 17, 749-755. doi:10.3758/PBR.17.5.749

De Jong, N. H., Schreuder, R., and Baayen, R. H. (2000). The morphological family size effect and morphology. Language and Cognitive Processes, 15:329-365. 
Devlin, J. T., Jamison, H. L., Matthews, P. M., \& Gonnerman, L. M. (2004). Morphology and the internal structure of words. Proceedings of the National Academy of Sciences of the United States of America, 101(41), 14984-8.

Diependaele, K., Sandra, D., \& Grainger, J. (2005). Masked crossmodal morphological priming: Unravelling morpho-orthographic and morpho-semantic influences in early word recognition. Language \& Cognitive Processes, 20, 75-114.

Dominguez, A., De Vega, M . \& Barber, H. (2004). Event-related brain potentials elicited by morphological, homographic, orthographic, and semantic priming. Journal of Cognitive Neuroscience, 16, 598-608.

Evans, N. \& Toshiki, O. (2005). Mundari: The myth of a language without word classes. Linguistic Typology, 9, 351-390.

Feldman, L.B. (2000). Are morphological effects distinguishable form the effects of shared meaning and shared form? Journal of Experimental Psychology: Learning, Memory and Cognition, 26, 1431-1444.

Feldman, L.B., \& Soltano, E.G. (1999). Morphological priming: The role of prime duration, semantic transparency and affix position. Brain and Language, 60, 3339

Feldman, L. B., Kostić, A., Gvozdenović, V., O’Connor, P. A. \& Moscoso del Prado Martín, F. (2012) Early morpho-semantic processing in Serbian: A violation of form-then-meaning accounts of word recognition. Psychological Bulletin and Review, 16, 684-91.

Feldman, L. B., O’Connor, P. A., \& Moscoso del Prado Martı'n, F. (2009). Early morphological processing is morpho-semantic and not simply morphoorthographic: Evidence from the masked priming paradigm. Psychonomic Bulletin \& Review, 16, 684 - 691. doi:10.3758/PBR.16.4.684 
Foley, W. (2008). The place of Philippine languages in a typology of voice systems. In

Peter K. Austin and Simon Musgrave (Eds.), Voice and Grammatical Relations in Austronesian Languages, p. 22-44. Stanford: CSLI Publications.

Frost, R., Deutsch, A., \& Forster, K. I. (2000). Decomposing morphologically complex words in a nonlinear morphology. Journal of Experimental Psychology: Learning, Memory and Cognition, 26(3), 751-765.

Giraudo, H., \& Grainger, J. (2001). Priming complex words: Evidence for supralexical representation of morphology. Psychonomic Bulletin \& Review, 8, 127-131.

Gold, B. T., \& Rastle, K. (2007). Neural correlates of morphological decomposition during visual word recognition. Journal of Cognitive Neuroscience, 19(12), 1983-1993.

Grainger, J. \& Ziegler, J. (2011) A dual-route approach to orthographic processing. Frontiers in Psychology 2:54. doi:10.3389/fpsyg.2011.00054.

Järvinen, T. (1994). Annotating 200 million words: the Bank of English project. In COLING 94. The 15th International Conference on Computational Linguistics Proceedings (pp. 565-568). Kyoto: Association for Computational Linguistics.

Kinkade, M. D. (1983). Salish evidence against the universality of 'noun' and 'verb'. Lingua, 21, 610-626.

Kiparsky, P. (1982). Lexical Morphology and Phonology. In I. S. Yand (ed.) Linguistics in the Morning Calm. Seoul Hanshin.

Lahiri, A. \& Reetz, H. (2010). Distinctive Features: Phonological underspecification in representation and processing. Journal of Phonetics, 38, 44-59.

Lavric, A., Clapp, A., \& Rastle, K. (2007). ERP evidence for morphological analysis from orthography: A masked priming study. Journal of Cognitive Neuroscience, 19, 866-877. doi:10.1162/jocn.2007.19.5.866 
Lavric A, Elchlepp H, Rastle K. (2012). Tracking hierarchical processing in morphological decomposition with brain potentials. Journal of Experimental Psychology: Human Perception and Performance, 38, 811-816.

Lavric, A., Rastle, K., \& Clapp, A. (2011). What do fully visible primes and brain potentials reveal about morphological decomposition? Psychophysiology, 48, 676-686. doi:10.1111/j.1469-8986.2010.01125.x

Leminen, A., Smolka, E., Duñabeitia, J. A., \& Pliatsikas, C. (2018). Morphological processing in the brain: the good (inflection), the bad (derivation) and the ugly (compounding). Cortex. http://doi.org/10.1016/j.cortex.2018.08.016

Lieber, R. (1980). On the organization of the lexicon. Doctoral Thesis. MIT, Cambridge Massachusetts, U.S.A.

Longtin, C. M., \& Meunier, F. (2005). Morphological decomposition in early visual word processing. Journal of Memory and Language, 53, 26-41.

Longtin, C.-M., Segui, J., \& Hallé, P. A. (2003). Morphological priming without morphological relationship. Language \& Cognitive Processes, 18, 313-334.

Marangolo, P., Piras, F., Galati, G . \& Burani, C. (2006). Functional anatomy of derivational morphology. Cortex, 42, 1093-1106.

Marslen-Wilson, W. D., Bozic, M. Randall, B. (2008). Early decomposition in visual word recognition: Dissociating morphology, form, and meaning. Language \& Cognitive Processes, 23, 394-421.

Marslen-Wilson, W. D., Tyler, L. K., Waksler, R., \& Older, L. (1994). Morphology and meaning in the English mental lexicon. Psychological Review, 101(1), 3-33.

McCormick, S. F. (2016, April 19). Word2Vec Tutorial - The Skip-Gram Model. Retrieved from http://www.mccormickml.com 
McCormick, S. F., Rastle, K. \& Davis, M. H. (2008). Is there a 'fete' in 'fetish'? Effects of orthographic opacity on morpho-orthographic segmentation in visual word recognition. Journal of Memory and Language, 58, 307-326.

McCormick, S. F., Brysbaert, M. \& Rastle, K. (2009). The Quarterly Journal of Experimental Psychology, 62 (9), 1706-1715

Meinzer, M., Lahiri, A., Flaisch, T., Hannemann, R., \& Eulitz, C. (2009). Opaque for the reader but transparent for the brain: Neural signatures of morphological complexity. Neuropsychologia, 47(8-9), 1964-71.

Meunier, F. \& Longtin, C.M. (2007). Morphological decomposition and Semantic Integration in Word processing. Journal of Memory and Language, 56, 457-471.

Morris, J., Frank, T., Grainger, J., \& Holcomb, P. J. (2007). Semantic transparency and masked morphological priming: An ERP investigation. Psychophysiology, 44, 506-521. doi:10.1111/j.1469-8986.2007.00538.x

Napps, S. E., \& Fowler, C. A. (1987). Formal relationships among words and the organization of the mental lexicon. Journal of Psycholinguistic Research, 16(3), $257-272$.

Plank, F. (1981). Morphologische (Ir)Regularitäten. Tübingen: Gunter Narr.

Plank, F. (2010). Variable direction in zero-derivation and the unity of polysemous lexical items. Word Structure, 3(1), 82-97.

Plaut, D. C., \& Gonnerman, L. M. (2000). Are non-semantic morphological effects incompatible with a distributed connectionist approach to lexical processing? Language and Cognitive Processes, 15(4/5), 445-485.

Pliatsikas, C., Wheeldon, L., Lahiri, A., \& Hansen, P.C. (2014). Processing of zeroderived words in English: An fMRI investigation. Neuropsychologia. 53, 47-53. R Development Core Team (2010). R: A language and environment for statistical 
computing. Vienna, Austria: R Foundation for Statistical Computing.

Rastle, K., \& Davis, M. H. (2008). Morphological decomposition based on the analysis of orthography. Language and Cognitive Processes, 23, 942-971. doi:10.1080/01690960802069730

Rastle, K., Davis, M. H., Marslen-Wilson, W. D., \& Tyler, L. K. (2000). Morphological and semantic effects in visual word recognition: A time course study. Language and Cognitive Processes, 15, 507-537. doi:10.1080/01690960050119689

Rastle, K., Davis, M. H., \& New, B. (2004). The broth in my brother's brothel: Morphoorthographic segmentation in visual word recognition.Psychonomic Bulletin \& Review, 11, 1090 -1098. doi:10.3758/BF03196742

Rueckl, J. G. \& Raveh, M. (1999) The influence of morphological regularities on the dynamics of a connectionist network. Brain and Language, 68, 110-117.

Rueckl, J. G. \& Aicher, K. A. (2008) Are CORNER and BROTHER morphologically complex? Not in the long term. Language and Cognitive Processes 23, 9721001.

Schuster, S., \& Lahiri, A. (in press). Lexical gaps and morphological decomposition: Evidence from German. Journal of Experimental Psychology: Learning, Memory, and Cognition.

Schuster, S., Scharinger, M., Brooks, C., Lahiri, A., \& Hartwigsen, G. (2018). The neural correlates of morphological complexity processing: Detecting structure in pseudowords. Human Brain Mapping. http://dx.doi.org/10.1002/hbm.23975

Smolka, E,, Preller, K. H. \& Eulitz, C, (2014). 'Verstehen' ('understand') primes 'stehen' ('stand'): Morphological structure overrides semantic compositionality in the lexical representation of German complex verbs. Journal of Memory and Language, 72, 16-36. 
Spencer, A. (1991). Morphological theory: An introduction to word structure in generative grammar. Oxford: Blackwell.

Sproat, R. \& Shih, C. (1992). On the sources of some constraints on Mandarin morphology. Proceedings of the Third International Symposium on Chinese Languages and Linguistics, 20-37.

Taft, M., \& Forster, K. I. (1975). Lexical storage and retrieval of prefixed words. Journal of verbal learning and verbal behavior, 9, 271-294.

Velan, H., \& Frost, R. (2011). Words with and without internal structure: what determines the nature of orthographic and morphological processing? Cognition, 118, 141-156.

Vigliocco, G., Vinson, D. P., Druks, J, Barber, H. \& Cappa, S. F. (2011). Nouns and verbs in the brain: A review of behavioural, electrophysiological, neuropsychological and imaging studies. Neuroscience and Biobehavioral Reviews, 35, 407-426.

Whiting, C. M., Marslen-Wilson, W. D. \& Shtyrov, Y. (2013). Neural dynamics of inflectional and derivational processing in spoken word comprehension: laterality and automaticity. Frontiers of Human Neuroscience, 7, 759. doi: 10.3389/fnhum.2013.00759 


\section{Appendix 1}

The one and two-step morphological primes and their associated semantic primes and controls used in Experiments 1 to 3. The targets were the stems of the morphological primes.

\begin{tabular}{|c|c|c|c|c|c|}
\hline $\begin{array}{l}\text { One step } \\
\text { biting }\end{array}$ & $\begin{array}{l}\text { Semantic } \\
\text { gnawing }\end{array}$ & $\begin{array}{l}\text { Control } \\
\text { waxing }\end{array}$ & $\begin{array}{l}\text { Two step } \\
\text { bleeping }\end{array}$ & $\begin{array}{l}\text { Semantic } \\
\text { honking }\end{array}$ & $\begin{array}{l}\text { Control } \\
\text { tanning }\end{array}$ \\
\hline blurring & smudging & tagging & bolting & locking & soaking \\
\hline bailing & paroling & sunning & lambing & birthing & scorning \\
\hline bruising & wounding & sleighing & brushing & combing & quizzing \\
\hline buzzing & hissing & shelling & potting & sowing & dreading \\
\hline clenching & gripping & plugging & roofing & thatching & hoaxing \\
\hline diving & plunging & greasing & salting & sprinkling & dodging \\
\hline flirting & teasing & clouding & scouting & spying & conning \\
\hline slitting & gashing & fibbing & shading & dimming & browsing \\
\hline scaring & daunting & cloaking & sleeting & hailing & bouncing \\
\hline thirsting & craving & bridging & veiling & masking & booming \\
\hline trekking & marching & boozing & wheeling & trundling & blending \\
\hline blending & merging & yachting & boozing & sipping & tricking \\
\hline booming & roaring & trimming & bridging & spanning & snoozing \\
\hline bouncing & vaulting & thumbing & cloaking & shrouding & spilling \\
\hline browsing & scanning & snacking & clouding & misting & grabbing \\
\hline conning & cheating & shipping & fibbing & faking & glaring \\
\hline dodging & swerving & seeding & greasing & oiling & delving \\
\hline dreading & fearing & rafting & plugging & clogging & churning \\
\hline hoaxing & fooling & spicing & shelling & peeling & bumping \\
\hline quizzing & probing & herding & sleighing & skiing & brewing \\
\hline scorning & jeering & camping & sunning & basking & bonding \\
\hline soaking & wetting & bossing & tagging & labeling & blushing \\
\hline tanning & bronzing & boating & waxing & glossing & breaching \\
\hline breaching & cleaving & wheeling & boating & rowing & thirsting \\
\hline blushing & glowing & veiling & bossing & reigning & trekking \\
\hline bonding & gluing & sleeting & camping & lodging & scaring \\
\hline brewing & steeping & shading & herding & swarming & slitting \\
\hline bumping & jolting & scouting & spicing & zesting & flirting \\
\hline churning & stirring & salting & rafting & canoeing & diving \\
\hline delving & sifting & roofing & seeding & planting & clenching \\
\hline glaring & scowling & potting & shipping & posting & buzzing \\
\hline grabbing & snatching & brushing & snacking & munching & bruising \\
\hline spilling & dribbling & lambing & thumbing & pawing & bailing \\
\hline snoozing & dozing & bolting & trimming & snipping & blurring \\
\hline tricking & scamming & bleeping & yachting & sailing & biting \\
\hline
\end{tabular}




\section{Appendix 2}

The one and two-step target words and their associated controls tested in Experiment 4.

$\begin{array}{lllll} & \text { One step } & \text { Control } & \text { Two step } & \text { Control } \\ 1 & \text { biting } & \text { a chant } & \text { bleeping } & \text { a mask } \\ 2 & \text { blurring } & \text { to gnaw } & \text { bolting } & \text { to dye } \\ 3 & \text { bailing } & \text { a cull } & \text { lambing } & \text { a truck } \\ 4 & \text { bruising } & \text { to wet } & \text { brushing } & \text { to snow } \\ 5 & \text { buzzing } & \text { a tip } & \text { potting } & \text { a gun } \\ 6 & \text { clenching } & \text { to lap } & \text { roofing } & \text { to grass } \\ 7 & \text { diving } & \text { a clash } & \text { salting } & \text { a hoe } \\ 8 & \text { flirting } & \text { to limp } & \text { scouting } & \text { to grit } \\ 9 & \text { slitting } & \text { a bow } & \text { shading } & \text { a skin } \\ 10 & \text { scaring } & \text { to lick } & \text { sleeting } & \text { to rope } \\ 11 & \text { thirsting } & \text { a snort } & \text { veiling } & \text { a palm } \\ 12 & \text { trekking } & \text { to cite } & \text { wheeling } & \text { to nail } \\ 13 & \text { blending } & \text { a poll } & \text { boozing } & \text { a coat } \\ 14 & \text { booming } & \text { to jab } & \text { bridging } & \text { to soil } \\ 15 & \text { bouncing } & \text { a chill } & \text { cloaking } & \text { a dish } \\ 16 & \text { browsing } & \text { to fuss } & \text { clouding } & \text { to barge } \\ 17 & \text { conning } & \text { a mass } & \text { fibbing } & \text { a block } \\ 18 & \text { dodging } & \text { to tow } & \text { greasing } & \text { to mop } \\ 19 & \text { dreading } & \text { a yell } & \text { plugging } & \text { a fence } \\ 20 & \text { hoaxing } & \text { to bob } & \text { shelling } & \text { to clap } \\ 21 & \text { quizzing } & \text { a sip } & \text { sleighing } & \text { a knee } \\ 22 & \text { scorning } & \text { to mull } & \text { sunning } & \text { to axe } \\ 23 & \text { soaking } & \text { a cheat } & \text { tagging } & \text { a cart } \\ 24 & \text { tanning } & \text { to jot } & \text { waxing } & \text { to beach } \\ 25 & \text { breaching } & \text { a groan } & \text { boating } & \text { a drum } \\ 26 & \text { blushing } & \text { to quest } & \text { bossing } & \text { to kid } \\ 27 & \text { bonding } & \text { a hike } & \text { camping } & \text { a toe } \\ 28 & \text { brewing } & \text { to jest } & \text { herding } & \text { to hook } \\ 29 & \text { bumping } & \text { a hug } & \text { spicing } & \text { a bait } \\ 30 & \text { churning } & \text { to loan } & \text { rafting } & \text { to claw } \\ 31 & \text { delving } & \text { a jibe } & \text { seeding } & \text { a dart } \\ 32 & \text { glaring } & \text { to choke } & \text { shipping } & \text { to lance } \\ 33 & \text { grabbing } & \text { a phase } & \text { snacking } & \text { a rake } \\ 34 & \text { spilling } & \text { to dock } & \text { thumbing } & \text { to oil } \\ 35 & \text { snoozing } & \text { a lash } & \text { trimming } & \text { a seed } \\ 36 & \text { tricking } & \text { to suck } & \text { yachting } & \text { to beef }\end{array}$

